\title{
Comprovando a Hipótese do Compromisso Convencional: Influência dos Pares Socionormativos Sobre as Condutas Desviantes em Jovens
}

Proving the hypotesis of the convencional commitment: Influence of the social-normative peers on the deviant conduct among youngsters

Nilton Soares Formiga

Universidade Federal da Paraíba
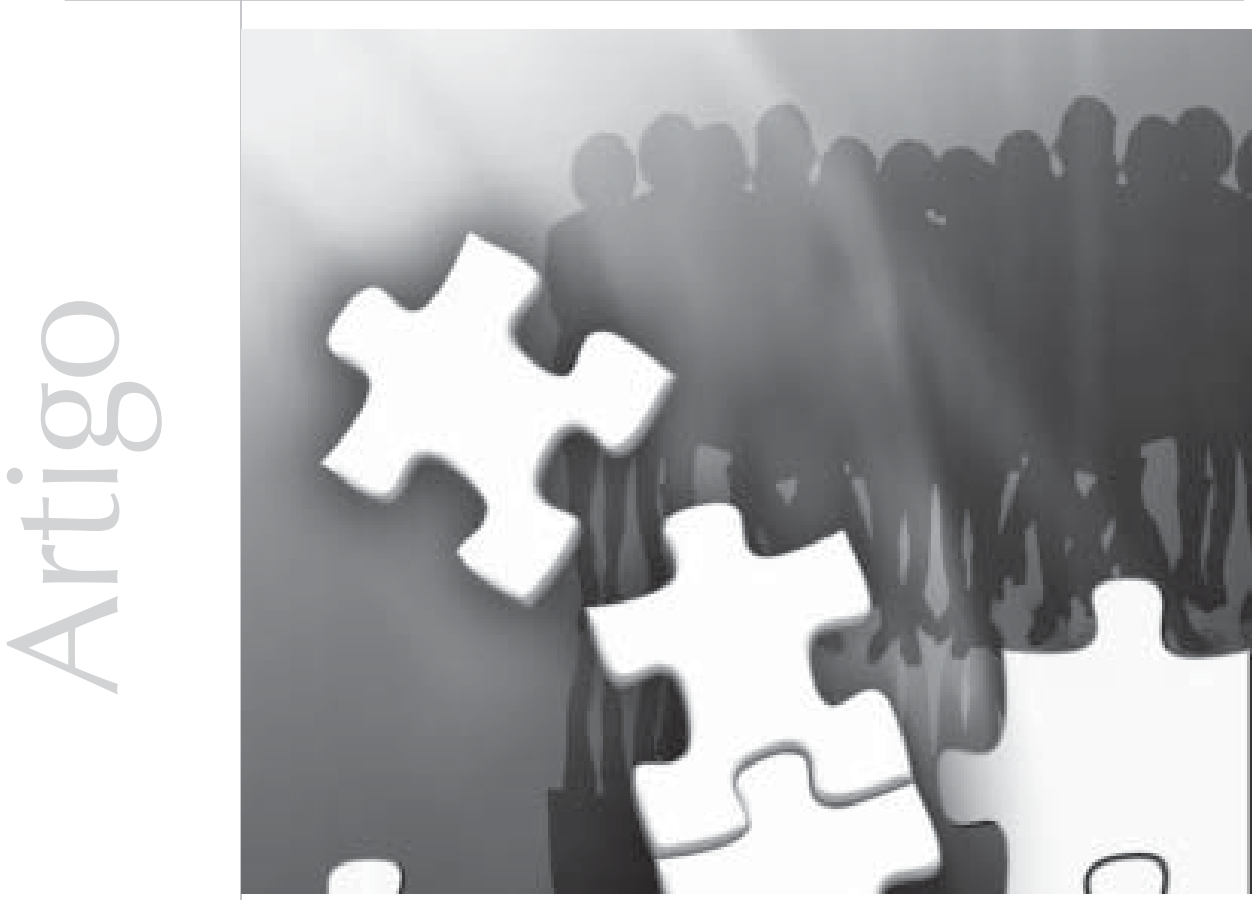

Durante o desenvol vimento deste trabalho,o autor contou com Bolsa de Produtividade Científica do CEULP-ULBRA (Proict), instituição a qual agradece. Meus agradecimentos aos alunos Ana Claudia Fachini, Cleomara Yepes, Faibana Curado, Igor Ayroza, Iracema Alves, Juciara Teixeira, Lunna Dias, Marília Pahim e Pollyana Prates pelos comentários e críticas emitidos a respeito do presente estudo. 


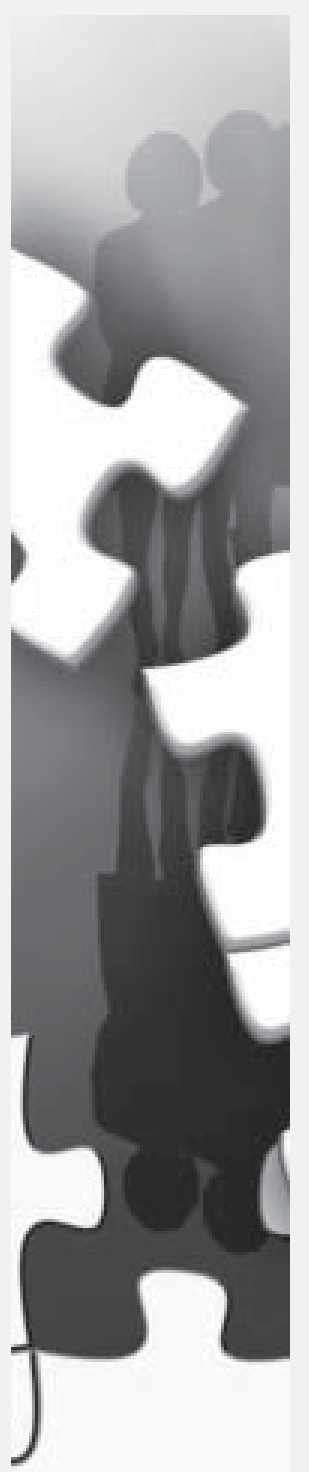

Resumo: As explicações sobre as condutas dos adolescentes têm sido relacionadas às diferenças individuais e psicossociais, porém, o foco na dinâmica funcional e estrutural da família vem pretendendo explicar esse fenômeno com maior consistência. Neste trabalho, procura-se avaliar a relação entre identidade com os pares socionormativos (pai, mãe e professores) e as condutas anti-sociais e delitivas. 901 jovens das cidades de João Pessoa e Palmas, entre 15 e 21 anos, de ambos os sexos, responderam a escala de condutas anti-sociais e delitivas e da identidade com pares socio-normativos (pai, mãe e professores).Foi encontrada uma correlação direta entre identidade com o pai, mãe e professor; por sua vez, esses pares relacionaram-se negativamente com ambas as condutas. A identificação com o pai, mãe e professores, além de contribuir para formação social e normativa dos jovens, contribuirá para o contínuo escola-família em direção a um fator de proteção juvenil.

Palavras-chave: compromisso convencional, pares, condutas anti-sociais e delitivas, jovens.

Abstract: The explanation about youngsters has been related to individual and psychosocial differences. However, the target in the functional and structural dynamic of the family tries to explain this phenomenon in a more consistent way. This work has the objective of evaluating the relation between identifications with the social-normative peers (father, mother and teachers) and the delictive and antisocial conducts. 901 youngsters from João Pessoa and Palmas, from 15 to 21 years old, male and female, answered the scale of antisocial and delictive conduct and also the social-normative identification peers scale(father, mother and teachers), but those groups had a negative relation with both conducts. The identification of youngsters with father, mother and teachers, besides contributing to the social and normative formation of youngsters, will also contribute to the family-school continuum towards a juvenile protection factor.

Key words: conventional commitment, peers, antisocial and delictive conducts, youngsters.

Na última década, tem sido possível acompanhar a investida de estudiosos em diversas áreas da ciência social e humana, buscando compreender o comportamento juvenil que apresente traços de delinqüência (por exemplo, formas de organização social que os jovens adotam (gangs), a criação de jogos de diversão violentos, balbúrdias em festas, vandalismo, alto consumo de álcool e fumo, etc.). Apesar das inúmeras variáveis que confirmam as explicações sobre esse problema, as quais podem ir da perspectiva sociodemográfica, personalística à psicossocial (Agüero, 1998; Stoff; Breiling; Maser, 1997; Tamayo; Nicaretta; Ribeiro; Barbosa, 1995), a família, porém, entendida tanto em sua estrutura quanto dinâmica funcional, ainda é alvo de preocupação reflexiva e empírica por parte dos pesquisadores e leigos que pretendem encontrar, a partir dela, a origem 
Mais do que vislumbrar como o jovem poderia agir quando fora do ambiente familiar, essas varióveis visam a contribuir para o bem-estar psicológico e a estabilidade socioemocional de toda a família e para a interpessoalidade entre os pares que a formam

Bee ; Formiga \& Outeiral das condutas tangenciadoras das normas sociais em jovens (Sukhodolsky; Colub; Cromwell, 2001; Torrente; Rodriguez, 2000). De fato, a relação familiar tem revelado muita importância na sua inter e intra-relação com a vida do jovem; mesmo na fase da adolescência, momento em que o jovem manifesta uma expressiva necessidade de autonomia frente aos laços familiares e às exigências dos pais, parece que o valor de tal instituição, para eles, não é dissolvido com facilidade, bem como o seguimento de uma norma socializada através da conduta e atitude das pessoas responsáveis pela transmissão do comportamento juvenil socialmente desejável. Mais do que vislumbrar como o jovem poderia agir quando fora do ambiente familiar, essas variáveis visam a contribuir para o bem-estar psicológico e a estabilidade socioemocional de toda a família e para a interpessoalidade entre os pares que a formam (Bee, 1997; Formiga, 2004; Outeiral, 1994). Dessa maneira, a família é o primeiro grupo em que a pessoa recebe uma formação individual e social (Ariés, 1981), promovendo a internalização, transmissão e manutenção moral e valorativa que permita chegar o mais próximo possível de uma predição das atitudes e comportamentos aceitos, não somente no transcorrer da vida juvenil, mas também na etapa adulta (Formiga; Oliveira; Curado; Lüdke; Teixeira; Facchini, 2003; Schneider, 2001). Com isso, essa instituição pode ser considerada "uma forma básica de ajuda mútua e suporte material e emocional, um local que possa nutrir e criar as gerações futuras" (Domingues, 2002; p.192).

Apesar do interesse na influência estrutural e funcional da família nas condutas dos jovens (Grossi et al, 2000; Torrente; Rodriguez, 2000) nas relações intra e interpessoais, em um estudo realizado por Formiga e Fachini (2003), no qual se buscava avaliar a consistência relacional do que os autores chamaram de identificação com endogrupos diários (por exemplo, grupos em que esses jovens convivem, em seu cotidiano como família, familiares, vizinhos, amigos e professores) e a conduta desviante (por exemplo, conduta antisocial e delitiva; farei referências a elas mais à frente) foi observado, em amostras sociodemograficamente diferentes, que esses endogrupos se relacionaram negativamente a tais condutas, isto é, quanto maior a proximidade com esses endogrupos, maior a probabilidade de inibição de condutas permeadoras da delinqüência, e isso independe da classe social. Porém, apesar de esse estudo ter trazido resultados satisfatórios em relação a uma micro-análise dessa instituição, a fim de seguir com o presente estudo, a crítica estaria quanto na variável da identificação endogrupal, que, ao invés de considerar essa quantidade de endogrupos, afinal nem todos poderiam se perceber como responsáveis ou como fator de proteção da conduta desviante dos jovens visando a um equilíbrio no excesso da busca de sensação, pois a convergência dos interesses e motivações terá maior probabilidade de ocorrência entre as aproximações de gerações mais novas, fato que funcionará algumas vezes, como uma espécie de excitador na quebra da norma social. Com isso, resolveu-se, a partir da base teórica que sustenta esse trabalho (ver Bolsoni-Silva; Marturano, 2002; Bronfenbrenner, 1994/1996), observar uma etapa mais específica e micro-identitária entre esses jovens, como, por exemplo, a identificação com os pares socionormativos, isto é, aqueles que são, psicossocialmente, responsáveis e atuam diretamente pelo estabelecimento e manutenção das condutas normativas dos jovens na sociedade (o pai, a mãe e o professor).

Ao investir nessa direção, a da identidade com os pares e a influência nas condutas em jovens, principalmente em relação às anti-sociais e delitivas, enfatiza-se o quanto eles, em termos afetivos, se assemelham a essas pessoas em seu cotidiano, já que estas são fatores humanos que procuram dar seguimento a uma formação de conduta e atitudes valorativas que correspondam a desejabilidade social. Tal fato 
parece ser comum quando acompanhamos os discursos diários em relação à continuidade família-escola, pais-professores, etc., concebidos como âncora na contribuição de um apoio para a formação psicológica e social, especialmente na orientação e transmissão de valores (Formiga, 2002b; Omar; Formiga; Delgado; Lüdke, 2003; Omar; Formiga; Uribe; Sampaio, 2004). Como considera Bronfenbrenner (1994/1996; ver também Polonia; Senna, 2005), tais interconexões possibilitam não somente a ampliação nas variações dos vínculos afetivocomportamentais e no desenvolvimento de papéis sociais mas também o estabelecimento de redes de informação e formação que possam estabelecer elos psicossociais inibidores dos fatores de risco para os jovens.

Dessa forma, ao considerar essa perspectiva, alguns estudos podem contribuir para a hipótese defendida: o estudo de Muñoz-Rivas e Graña (2001), além de considerar a estrutura familiar e sua influência no consumo de drogas lícitas e ilícitas, incluiu uma variável sobre relações afetivas com os pais; de acordo com esses autores, quanto maior o vínculo afetivo do jovem com o pai e a mãe, maior será a capacidade de inibição da conduta consumidora de drogas. Da mesma forma, Villar, Luengo, Gómez e Romero (2003), ao explicarem a conduta de drogadição, destacam que a escassez afetiva entre pais e filhos não é somente um fator de risco no uso dessas substâncias e da conduta delitiva, mas também leva o sujeito a baixa auto-estima e mau rendimento escolar. Outro trabalho que enfatiza a mesma variável foi desenvolvido por Grossi et al. (2000); também para eles, o laço afetivo e a boa comunicação entre pai e filho é capaz de manter uma relação familiar que satisfaça as necessidades dos membros em diferentes fases de seu desenvolvimento, contribuindo para a prevenção de futuros comportamentos capazes de permear a delinqüência. Isso foi comprovado quando estudaram 87 jovens de um centro penitenciário de Villabona, na Espanha, observando que os jovens detidos nesse centro apresentaram, em sua família, maus-tratos, déficit nas relações afetivas e baixo nível de comunicação.

Ao referir-se ao construto sobre identidade, esse estudo não somente inclui o processo de socialização mas também o grau em que os jovens se sentem próximos, em termos afetivos e motivacionais, de cada um dos pares, por exemplo, pai, mãe e professores, devendo esse construto incluir um processo de mediação que pode ser assim representado: jovem ? conduta subjetiva ? pares, daí enfatizarse a importância de uma interdependência nessa tríade. A saliência, nessa perspectiva, deve-se ao fato de que, no processo de maturação biopsicossocial do jovem, é comum a espontaneidade, iniciativa e mudança, visando à exigida 'liberdade' que, na maioria das vezes, ocorre desordenada, extravagante e com excessivo desenvolvimento de uma auto-imagem diferente de todos, justificada pela busca da autonomia e realização pessoal. Com isso, é a partir dessa perspectiva que eles talvez não consigam organizar e desenvolver cognitivamente a diferenciação entre uma conduta ideal e uma real (Lane, 1995; Fraga, 2000) bem como não possam ir de encontro ao que é socialmente aceito entre os pares . Ao considerar a identidade que os jovens possam ter com esses pares, aquela vem contribuir não apenas para a inibição das condutas delinqüentes mas também para um melhor desenvolvimento psicológico e social para ambos; segundo Mulvey e Cauffman (2001), apesar de os jovens estarem avançando em seu desenvolvimento em termos da formação das diferenças individuais, estas ainda não estão totalmente formadas, o que impede a avaliação consistente da rápida mudança das suas condutas e da sua interação com as pessoas de sua convivência, fatores que interferem na formação de habilidades sociais. Assim, é por isso que se enfatiza a necessidade, de acordo com esses autores, da elaboração de estratégias que coloquem escola, família e comunidade em programas contra a delinqüência. 
Dessa maneira, nesse momento caracterizado pela diferenciação, quando o jovem se afasta da família aderindo ao seu grupo de iguais, podem ocorrer comportamentos dos mais diversos, os quais podem ir desde a experiência com as drogas, arrogâncias (verbal e atitudinal), brincadeiras ilimitadas e atemporais, etc., até a pessoais e sociais (Dolcini; Adler, 1994; Sussman; Dent; McCullar, 2000). Na concepção de Dolcini e Adler (1994), tal fato ocorre porque os jovens, geralmente, sofrem pressão na sua inserção grupal, sendo-lhes exigido não só que assumam condutas vividas por seu grupo bem como que satisfaçam os membros que o compõem e busquem auto-afirmação a partir de uma não-conformidade às normas, papéis e leis dos responsáveis para sua formação normativa. É nesse momento que as normas de seus grupos de iguais são mais importantes do que as da família ou as escola; afinal, estes últimos impõem limites e controles, e tais condições é o que os jovens menos querem, já que passam a viver e desejar novas experiências (Coelho Junior; Formiga; Oliveira; Omar, 2004; Gullone; Moore, 2000), direcionando as atividades de risco.

Assim, ao destacar as condutas anti-sociais e delitivas, tomou-se como base o estudo de Formiga e Gouveia (2003); para esses autores, uma conduta anti-social se refere à nãoconscientização das normas que devem ser respeitadas. Sabe-se da norma de limpeza das ruas ou do respeito com os colegas quanto a certas brincadeiras, porém estas não são praticadas por alguns deles. Com isso, uma das características dessas condutas é o fato de incomodarem, mas sem causar, necessariamente, danos físicos a outras pessoas; dizem respeito apenas às travessuras dos jovens ou simplesmente à busca de romper com algumas leis sociais (Formiga; Gouveia, 2003). No que diz respeito às condutas delitivas, elas são concebidas, por esses autores, como merecedoras de punição, capazes de causar danos graves, morais e/ou físicos, sendo consideradas mais severas que as anteriores, já que representam ameaça iminente à ordem social em vigor.

Por fim, o presente estudo compreende um delineamento do tipo correlacional, considerando variáveis antecedentes a identidade com pares socionormativos e variáveis critérios as condutas anti-sociais e delitivas. Assim, tem como objetivo observar o grau de identidade que os jovens têm com as pessoas que contribuem para a sua formação social, moral e valorativa - por exemplo, pai, mãe e professor - e a relação com as condutas anti-sociais e delitivas; no que tange às hipóteses, foram formuladas as seguintes:

Hipótese 1: A identidade com o pai, a mãe e o professor estarão relacionados, negativamente, às condutas anti-sociais e delitivas.

Hipótese 2: A identidade com o pai, a mãe e o professor estão relacionadas, positivamente, entre si.

\section{Método}

\section{Amostra}

901 jovens compuseram a amostra, o quais foram distribuídos igualmente nos níveis escolares fundamental e médio da rede privada e pública de educação da cidade de João Pessoa - PB. Os respondentes foram de ambos os sexos, predominando ligeiramente a participação de mulheres $(52,1 \%)$. Estas apresentaram idades entre 15 e 21 anos, sendo a maioria solteira $(93,8 \%)$, e, entre as classes sociais média e alta, juntos correspondiam, aproximadamente, a $87 \%$ dessa classe social a que objetivava o estudo.

Tal amostra foi não probabilística, e, sim, intencional, pois, além do propósito de garantir a validade externa dos instrumentos da pesquisa, era assegurada a possibilidade de realizar as análises estatísticas que permitissem 
estabelecer as relações entre as variáveis a serem estudadas.

\section{Instrumentos}

Os participantes responderam um questionário composto das seguintes medidas:

Escala de condutas anti-sociais e delitivas: esse instrumento, proposto por Seisdedos (1988) e validado por Formiga e Gouveia (2003) para o contexto brasileiro, compreende uma medida comportamental em relação às condutas anti-sociais e delitivas. Tal medida é composta por quarenta elementos, distribuídos em dois fatores, como se segue: condutas antisociais: seus elementos não expressam delitos, mas comportamentos que desafiam a ordem social e infligem normas sociais (por exemplo, jogar lixo no chão mesmo quando há perto um cesto de lixo; tocar a campainha na casa de alguém e sair correndo). As condutas delitivas incorporam comportamentos delitivos que estão fora-da-lei, caracterizando uma infração ou uma conduta faltosa e prejudicial a alguém ou mesmo à sociedade (por exemplo, roubar objetos dos carros; conseguir dinheiro ameaçando pessoas mais fracas). Para cada elemento, os participantes deveriam indicar o quanto apresentavam o comportamento assinalado no seu dia a dia. Para isso, utilizavam uma escala de resposta com dez pontos, tendo os seguintes extremos: $\mathbf{0}=$ Nunca e $\mathbf{9}=$ Sempre.

Questionário da identidade com pares socionormativos: nesse instrumento, o sujeito era orientado a responder as questões relativas a sua identificação com os endogrupos, isto é, eles deveriam assinalar, marcando com um círculo ou $\mathbf{X}$, numa escala tipo Likert de cinco pontos, que variava de $\mathbf{0}=$ Não me identifico totalmente a $\mathbf{5}$ = Identifico-me totalmente, o quanto se assemelhavam a cada um dos respondentes do questionário, por exemplo, pai, mãe e professores. Para isso, tinham como foco a contribuição que cada um deles dava, de forma contínua, para sua formação social e normativa.
Caracterização sociodemográfica: foram elaboradas perguntas que contribuíram para caracterizar os participantes deste estudo (por exemplo, sexo, idade, estado civil, classe social).

\section{Procedimento}

Para a aplicação do instrumento, o responsável pela coleta dos dados visitou a coordenação ou diretoria das instituições de ensino, falando diretamente com os diretores e/ou coordenadores para depois tentar a permissão, junto aos professores responsáveis pela disciplina, para ocupar uma aula e aplicar os questionários. De posse de tal autorização, foi exposto, sumariamente, o objetivo da pesquisa, solicitando a participação voluntária dos jovens. Um único aplicador, previamente treinado, esteve presente em sala de aula. Sua tarefa consistiu em apresentar os instrumentos, solucionar as eventuais dúvidas e conferir a qualidade geral das respostas emitidas pelos respondentes. Assegurou-se a todos o anonimato e a confidencialidade das suas respostas, indicando que estas seriam tratadas estatisticamente no seu conjunto.

\section{Tabulação e análise dos dados}

Para a análise dos dados, foi utilizado o pacote estatístico SPSSWIN em sua versão 11.0, no qual foram efetuadas análises descritivas (medida de dispersão e tendência central) e computadas correlações de Pearson (r), bem como o cálculo do qui-quadrado (c $\left.{ }^{2}\right)$.

\section{Resultados e discussão}

A fim de atender os objetivos deste estudo, expressos na hipótese 1 e 2, foi efetuada uma correlação de Pearson (r); a partir desse cálculo, observaram-se os seguintes resultados, apresentados em destaque na tabela 1 , que foram capazes de confirmar a hipótese 1. 
Tabela 1- Correlações entre pares socionormativos e as condutas anti-sociais e delitivas.

\section{Pares socionormativos}

Pai

Mãe

Professor

\begin{tabular}{|l|c|c|}
\hline \multicolumn{3}{|c|}{ Tipo de conduta } \\
\hline Anti-Sociais & Delitivas & CAD \\
\hline$-0,19^{*}$ & $-0,12^{*}$ & $-0,18^{*}$ \\
\hline$-0,16^{*}$ & $-0,15^{*}$ & $-0,17^{*}$ \\
\hline$-0,21^{*}$ & $-0,19^{*}$ & $-0,23^{*}$ \\
\hline
\end{tabular}

Notas: ${ }^{*} p<0,001$ (teste unilateral; eliminação pairwise de casos em branco); CAD = Pontuação total das condutas anti-sociais e delitivas.

Na tabela acima, os pares considerados responsáveis pela formação socionormativa dos jovens apresentaram correlações negativas com ambas as condutas, a saber: o pai relacionou-se negativamente com as condutas anti-sociais $(r=-0,19, p<0,001)$, delitivas $(r=-0,12, p<$ $0,001)$ e as condutas desviantes (CAD = pontuação total das condutas anti-sociais e delitivas) $(r=$ $-0,18, \mathrm{p}<0,001)$; a mãe também apresentou correlações negativas para as mesmas condutas, respectivamente $(r=-0,16, p<0,001),(r=-0,15, p<0,001)$ e $(r=-0,17, p<0,001)$; o mesmo ocorreu para a identidade com o professor, relacionando inversamente as condutas antisociais $(r=-0,21, p<0,001)$, delitivas $(r=-0,19, p<0,001)$ e CAD $(r=-0,23, p<0,001)$. Assim, quanto maior a identificação com esses pares, maior a probabilidade de que esses jovens não apresentem as condutas permeadoras da delinqüência.

Tendo encontrado as correlações negativas entre os pares - pai, mãe e professor - e as condutas anti-sociais e delitivas, o que permitiu corroborar a primeira hipótese, o próximo passo destinou-se à avaliação da relação interna entre esses pares. Para isso, tomou como base hipotética a seguinte proposição, que forma a hipótese 2: é possível que esses pares estejam relacionados entre si, garantindo apoio e controle ao comportamento normativo entre os jovens, vindo a tornar consistente um fator de proteção frente aos tipos de condutas permeadoras da delinqüência (Formiga, 2002a; Formiga; Fachini, 2003). Assim, na tabela 2, pode ser encontrado o resultado que aponta a comprovação dessa hipótese; todos os pares estiveram correlacionados entre si, isto é, a identidade com o pai relacionou-se diretamente com a mãe $(r=0,45, p<0,001)$ e estes com o professor, respectivamente, $(r=0,19, p<0,001)$ e $(r=0,17, p<0,001)$.

Tabela 2 - Correlações internas entre pares socionormativos.

\begin{tabular}{|c|c|c|c|c|c|}
\hline & & & Pai & Mãe & Professor \\
\hline Pares socio normativos & $\mathbf{M}$ & DP & & & \\
\hline Pai & 4,09 & 1,45 & - & & \\
\hline Mãe & 4,60 & 0,95 & $0,45^{*}$ & - & \\
\hline Professor & 3,04 & 1,50 & $0,19^{*}$ & $0,17^{*}$ & - \\
\hline
\end{tabular}

Notas: ${ }^{*} p<0,001$ (teste unilateral; eliminação pairwise de casos em branco).

Dessa maneira, parece haver um contínuo da identidade entre os pares, permitindo pensar numa base dinâmica capaz de contribuir para o segmento de um fator de proteção para o jovem. Em resultado semelhante, porém tratando de outra variável, por exemplo, sobre indicadores do rendimento escolar, Formiga (2002b) observou que a identificação com a família (pai e mãe) e os professores contribui para que o jovem dedique mais tempo aos estudos, com 
aumento no auto-conceito como estudante e melhores notas semestrais; vale destacar que, no estudo desse autor, também foi encontrada uma relação direta entre esses pares. Ainda na mesma linha de estudo, mas utilizando um instrumento diferente do proposto por Formiga e Gouveia (2003) para atender o objetivo do presente estudo quanto à avaliação do comportamento delinqüente, foi encontrada, por Crosnoe, Erickson e Dornbusch (2002) a mesma relação; esses últimos autores concluíram que, para inibir os comportamentos desviantes na escola e comunidade do entorno, faz-se necessário criar oportunidades positivas que possam envolver professores, alunos e família bem como um investimento para a conscientização de que, em ambas as instituições, existem normas e sanções que devem ser cumpridas e que visam, além da prevenção dessa conduta, a um apoio para o bem-estar psicológico de todos.

Com isso, os resultados encontrados e apresentados na tabela 2 sustentam o discurso cotidiano, onde escola e família podem trabalhar juntas, intervindo nas condutas dos jovens e promovendo um acompanhamento dialógico entre a tríade família-jovem-escola quanto à intervenção nessas condutas, visando a formá-los e protegê-los dos danos físicos e morais. É possível, com esse resultado, observar uma convergência como uma parte do modelo da delinqüência elaborado por Frías, López-Escobar e Díaz-Méndez (2003; ver também, Mulvey; Cauffman, 2001), que consideram ser a escola um ambiente que vai além do ensino e apreensão do conhecimento e aprendizagem; para eles, a instituição escolar é capaz de influenciar os jovens tanto por normas, regras e costumes quanto na condição de um clima escolar que proporcione oportunidades para o sucesso escolar e relacionamentos interpessoais positivos, visando a assumirem condutas socialmente desejáveis (Formiga; Fachini, 2003). Nesse provável sistema da convencionalidade do compromisso normativo entre os jovens, incluindo numa lineariedade escola-família, há a atuação desses jovens que confronta as orientações dadas pelos pais e professores.

Observando esses resultados, é possível conduzir esses jovens à percepção e à concretização de uma escola e entorno urbano-escolar seguros (Kitsantas; Ware; Martinez-Arias, 2004) a partir de um investimento na reorganização do sistema intra e interfamiliar e de políticas públicas destinadas à prevenção das condutas desviantes. Assim, para maior esclarecimento quanto à configuração desse sistema, optou-se, na elaboração da figura 1, pela representação dos resultados encontrados. Nela, são contempladas as tabelas 1 e 2, sendo possível observar a representação de um modelo teórico organizado a partir das correlações. Assim, não só esses pares apresentam relações inversas para as condutas desviantes bem como estão relacionados entre si, vislumbrandose, assim, um possível modelo relacional preventivo das condutas destacadas no presente estudo (ver figura 1).

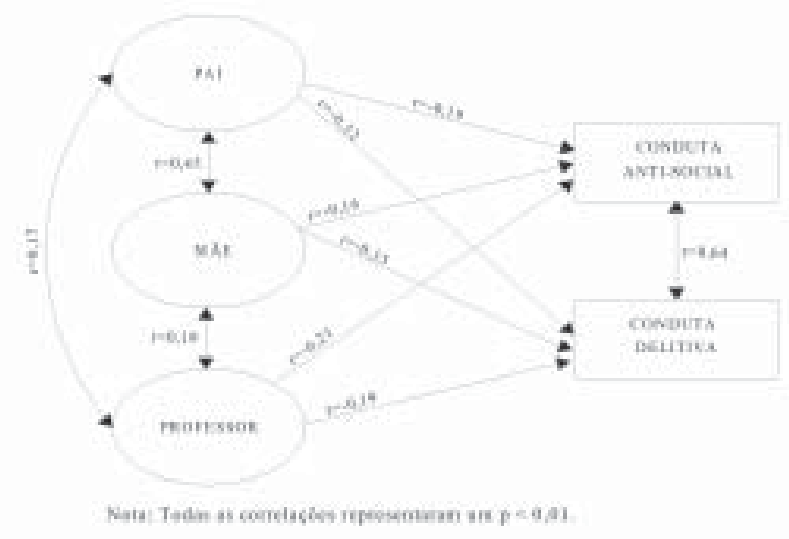

Figura 1- Representação gráfica da hipótese do compromisso convencional e as condutas desviantes em jovens 
Tal fato parece confirmar as reflexões de Reid e Eddy (1997), que compreendem que escola e família fazem parte da involução ou evolução desenvolvimentista das condutas anti-sociais juvenis, principalmente esta última, quando os pares que compõem ambas as instituições sociais (por exemplo, pais e professores) não conseguem identificar, em suas relações interpessoais, um baixo envolvimento afetivo, excesso de retaliação, baixa assertividade e segurança na colocação de limites, pouca ou nenhuma supervisão disciplinar, etc., o que se torna fator de risco para os jovens. Dessa maneira, essa poderia ser mais uma peça para encaixar no quebra-cabeça em relação ao aumento da delinqüência nos ambientes familiares e escolares, conduzindo à observação desses eventos e oportunizando uma orientação e comunicação empática e dialógica que enfatize as estratégias educativas de valoração e responsividade ou exigência diante dessas condutas desviantes seriam mais apropriadas e formadoras (ver Costa; Gomes; Teixeira, 2000; Formiga; Oliveira; Curado; Lüdke; Teixeira; Fachini, 2003; Wagner; Ferreira; Rodrigues, 1998) de condutas reflexivas quanto ao perigo e prejuízo humano e social.

Com isso o poder dos pais e outros adultos, nesse caso, os professores, seria de muita importância para o monitoramento do desenvolvimento social desses garotos, tanto fora quanto dentro da escola e da família. Porém, o que deve ficar claro, aqui, é o que se refere à formação e orientação do comportamento socialmente desejável, e não a um enrijecimento das normas e da verdade única dos pais e da escola para fechá-lo em uma só conduta, a que todos gostariam que ele apresentasse. Afinal, eles vivem numa fase em que a busca por estímulos novos, a espontaneidade e constante iniciativa à mudança parecem ocorrer desordenadas e extravagantes, em direção à autonomia e realização pessoal.

Como dado adicional, a partir de uma análise descritiva (média e desvio padrão), foi encontrada, ainda na tabela 2, uma hierarquia identitária para esses jovens. Sendo assim, a mãe apresentou média superior $(M=4,60$; $D P$ $=0,95)$ ao pai $(M=4,09 ; \mathrm{DP}=1,45)$, e este, superior ao professor $(M=3,04$; $D P=$ 1,50). Dessa forma, além de serem os pares - pai, mãe e professor - relacionados diretamente entre si, e negativamente, as condutas anti-social e delitiva, hierarquicamente, a mãe, o pai e o professor contribuem para a construção de fatores de proteção entre os jovens, mantendo, assim, a existência do compromisso convencional, isto é, parece existir uma cascata na orientação das condutas normativas para esses jovens, podendo-se pensar que, entre esses pares, as práticas socionormativas se diferenciam bem como seguem certa hierarquização de poderes.

Encontradas as relações entre essas variáveis, o que foi tomado como dado adicional, procurou-se avaliar, a partir de uma análise descritiva, o grau de identidade que os jovens tem com os pares e a intensidade das condutas anti-sociais e delitivas. Considerando o cálculo da moda para as escalas estudadas, foi obtido um corte, com uma divisão em duas partes iguais, tendo as respostas dos sujeitos sido colocadas em extremos. De escala tipo Likert, passamos a obter uma escala de resposta binomial; dessa forma, para as condutas antisociais e delitivas, resolveu-se considerar Nunca $=1$ e Sempre $=2$. O mesmo se deu para a identificação com os pares, Não se Identifica $=1$ e Identifica-se totalmente $=2$; na tabela 3, são apresentados esses resultados.

A partir do cálculo de qui-quadrado, observouse que, para os pares aqui estudados, quanto maior a identificação com eles menor a intensidade das condutas anti-sociais e delitivas (ver tabela 3). Assim, em relação às condutas anti-sociais, para mais de $50 \%$ dos jovens que muito se identificam com o pai ( $\mathrm{c}^{2}=6,49$; $\mathrm{p}<0,05)$, a mãe $\left(\mathrm{c}^{2}=6,86 ; \mathrm{p}<0,05\right)$ e o professor $\left(c^{2}=6,05 ; p<0,05\right)$, esse tipo de conduta mostrou ter baixa intensidade entre eles. Considerando a conduta delitiva, foi possível encontrar resultados semelhantes aos da conduta anti-social. Mais da metade, 
aproximadamente $60 \%$ dos jovens que pontuaram essa conduta, também com uma alta identificação com o pai $\left(c^{2}=6,79 ; p<0,05\right)$, a mãe $\left(c^{2}=5,29 ; p<0,05\right)$ e o professor $\left(c^{2}=6,74 ; p<\right.$ $0,05)$, apresentaram menor intensidade à conduta delitiva.

Tabela 3 - Freqüência em percentagem da identificação com os pares sócio-normativos e a intensidade das condutas anti-sociais e delitivas.

\section{Identidade Com Pares Sócio-normativos} Baixa

Pai

$\begin{array}{ll} & \text { Alta } \\ \text { Mãe } & \text { Baixa }\end{array}$

Alta

Baixa

Professor
Alta

\section{Condutas}

\begin{tabular}{|l|l|l|l|}
\hline \multicolumn{2}{|c|}{ Anti-sociais } & \multicolumn{3}{l|}{ Delitivas } \\
\hline Baixa & Alta & Baixa & Alta \\
\hline & & & \\
\hline 51 & 49 & 54 & 46 \\
\hline $\mathbf{5 3}$ & 47 & 56 & 44 \\
\hline 51 & 49 & 54 & 46 \\
\hline $\mathbf{5 7}$ & 43 & $\mathbf{6 0}$ & 40 \\
\hline $\mathbf{4 6}$ & 54 & 51 & 49 \\
\hline & & & \\
\hline $\mathbf{5 5}$ & 45 & $\mathbf{6 0}$ & 40 \\
\hline
\end{tabular}

Notas: as percentagens em negrito apresentaram um $\mathrm{p}<0,05$.

Considerando esses resultados, pode-se afirmar que as hipóteses formuladas foram confirmadas. Ao observar que esses pares estão relacionados entre si, isto é, que pai, mãe e professores apresentam uma convergência de identidade para esses jovens, conclui-se que tal fato pode contribuir para programas de intervenção das condutas anti-sociais e delitivas, nos quais seria importante apontar uma aplicação sistêmica, onde professor e família trabalhassem paralelamente na orientação dos seus adolescentes. Afinal, somente os professores poderão atentar para algumas das condutas não observadas pelos pais durante o período em que esses jovens passam na escola, sendo que eles, com suas atitudes, seriam capazes de dar seguimento à formação moral e valorativa fomentada pela família bem como orientá-la na direção de condutas socialmente aceitas quando as normas sociais forem quebradas.

A relação entre as variáveis se revelou bem semelhante aos estudos realizados por Formiga (2002a; Formiga; Fachini, 2003) e Coelho Júnior (2001). Para esses autores, a explicação das condutas que foram tratadas neste estudo também evidencia a não observância das normas e regras sociais; os jovens que apresentaram maior pontuação correlacional na identidade com os pares socionormativos (pai, mãe e professores) o fizeram também inversamente nas condutas anti-sociais e delitivas e no uso potencial de drogas. De fato, o compromisso e adesão a esses pares normativos são de extrema importância por terem a função de transmitir valores e formarem traços de personalidade (Omar; Formiga; Uribe; Sampaio, 2004; Loehlin, 1997), que ocorrem durante a socialização e são capazes de promover uma adolescência auto-consciente, humana e com uma tendência às condutas de apoio social a outros jovens que apresentem condutas permeadoras da delinqüência.

Dessa maneira, parece evidente que as condutas desviantes são um reflexo da debilidade dos limites convencionais, principalmente quando se trata do afastamento do vinculo afetivo, podendo ser entendidas como a falta de comprometimento com os pares tradicionais e suas forças socializadoras para um comportamento socialmente aceito e 
a adesão débil aos papéis sociais convencionais, que esses pares (professores, família e, especialmente, os pais) apresentam como um caminho em direção tanto a uma melhor formação quanto como fator de proteção social e psicológica. Assim, essa convencionalidade em direção da inibição da conduta anti-social entre os jovens seria de extrema importância se, e somente se, estivessem envolvidos escola e família numa união entre eles, buscando promover melhores oportunidades para o seu engajamento em atividades socializadoras de esclarecimento quanto ao valor do outro e seus impactos psicossociais.

A qual, por sua vez, teria poder de fomentar entre pais, filhos e professores uma forte ligação afetiva (Crosnoe; Erickson; Dornbusch, 2002), investindo no desenvolvimento de habilidades sociais entre os professores a fim de instituir um fator de proteção e de identificação contra o desvio comportamental manifestado em sala ou em casa, junto à família. Não se trata de controle excessivo e de perda da expansão de conduta dos jovens, mas, sim, de poder acompanhá-los tanto de forma individual quanto interpessoal, já que, para os pais, existe toda uma construção da imagem sobre o filho, como a de nunca ter feito algo contrário e fora de suas orientações.

Mas uma vez, vale destacar que, com esses resultados, poderia ser proposto um programa de intervenção que objetivasse analisar filhosalunos, que são os mesmos fisicamente, porém, com diferenças quanto aos comportamentos quando se varia o contexto e as pessoas em seus relacionamentos interpessoais. É bem possível que, a partir do grau de identidade dos jovens em relação a esses pares, a responsabilidade de ambas as instituições possa ter maior peso, utilizando-se mais o diálogo e a conscientização de suas atitudes do que as imposições e castigos quando uma norma ou regra social é rompida. Dessa forma, esse programa não somente teria efeito positivo na orientação escolar mas também na adoção de práticas parentais firmes, permeando-as de autoridade e indulgência em vez de permissividade e negligência (Formiga; Oliveira; Curado; Lüdke; Teixeira; Fachini, 2003; Mulvey; Cauffman, 2001). Estas últimas, quando não esclarecidas e centradas na rigidez comportamental como controle da vida do filho, podem desencadear, possivelmente, maus-tratos e relação pais-jovens e professores-jovens inadequada, levando o jovem a conversar apenas para não ter que sofrer o castigo ou não se dirigir a eles porque parece já saber o que vai ser dito (discurso de que ele está errado, que sempre faz as coisas sem prestar atenção, que não é "perfeito", etc.), ao invés de promover uma autoconscientização e atualização dos direitos e deveres de cada um.

Assim, quando os adolescentes não se sentem envolvidos ou comprometidos com a instituição da qual fazem parte ou com as pessoas que a compõem, nesse caso, a família e a escola, onde poderiam apoiar-se emocional e socialmente, não serão capazes de internalizar valores, padrões convencionais e habilidades sociais maduras e tampouco de organizar-se em termos de traços de personalidade que venham contribuir para um comportamento segundo as normas sociais vigentes. Dessa maneira, além do conjunto família e escola, merece ser destacada a importância significativa da relação com indivíduos dessas instituições na prevenção das condutas desviantes. Por fim, a explicação dos comportamentos desviantes a partir da identidade com os pares vem assegurar o grande valor e a influência que família e escola venham a ter na formação e nas estratégias dos comportamentos dos jovens em nossa sociedade, focalizando, com isso, atividade preventiva onde não se observe apenas o jovem, mas todo o seu contexto sociohumano.

\section{Nilton Soares Formiga}

Mestre em Psicologia social pela Universidade Federal da Paraíba. Atualmente, é professor na mesma Universidade - UFPB. Avenida Guarabira, 133. Bairro de Manaíra.

CEP.: 58038-140João Pessoa - PB. E-mail: nsformiga@yahoo.com.

Recebido 12/04/05 Reformulado 17/10/05 Aprovado 28/11/05 
AGÜERO, A. J. El Trastorno de Conducta en la Infancia como Precursor del Trastorno Antisocial del Adulto. Estudios de Seguimiento a Medio y Largo Plazo. Necesidad de Programas Preventivos. Revista Electrónica de Psiquiatria, v. 2, Ilhas Baleares, 1998, pp.1-9.

ARIÉS, P. História Social da Criança e da Família. Rio de Janeiro: Guanabara, 1981.

BEE, H. O Ciclo Vital. Porto Alegre: Artes Médicas, 1997.

BOLSONI-SILVA, A. T.; MARTURANO, E.M. PráticasEducativaseProblemas de Comportamento: uma Análise à Luz das Habilidades Sociais. Estudos de Psicologia, v. 7, n. 2, Natal, 2002, pp. 227-235.

BRONFENBRENNER, U. A Ecologia do Desenvolvimento Humano: Experimentos Naturais e Planejados. Porto Alegre: Artmed. 1994/1996.

COELHO JUNIOR, L. L Uso Potencial de Drogas em Estudantes do Ensino Médio: suas Correlações com as Prioridades Axiológicas. Dissertação de Mestrado em Psicologia. Universidade Federal da Paraíba, 2001.

COELHOJUNIOR, L. L.; FORMIGA, N. S.; OLIVEIRA, A. R. N; OMAR, A.Considerações sobre a Influência da Busca de Sensações sobre o Uso Potencial de Drogas em Jovens. VI Congresso Brasileiro de Epidemiologia: um Olhar sobre a Cidade. Recife-PE. 19 a 23 de junho de 2004. [Resumo eletrônico-CD-ROM1415-790X).

COSTA, F. T.; GOMES, W. B.; TEIXERA, M. A. P. Responsividadee Exigência: duas Escalas para Avaliar Estilos Parentais. Psicologia: Reflexãoe Crítica, n. 13, v. 3, Porto Alegre, 2000, pp. 465-473.

CROSNOE, R.; ERICKSON, K. G.; DORNBUSCH, S.M. Protective Functions of Family Relationships and School Factors on the Deviant Behavior of Adolescent Boys/Girls: Reducing the Impact of Risky Friendships. Youth \& Society, v. 33, n. 4, Thousand Oaks, 2002, pp. 515-544.

DOLCINI, M. M.; ADLER, N. E. Perceived Competencies, Peer Group Affiliation and Risk Behavior among Early Adolescents. Health Psychology, v. 13, n. 6, Washington, 1994, pp. 496-506.

DOMINGUES, J. M. As Formas Fundamentais da Solidariedade Contemporânea. In Interpretando a Modernidade: Imaginário e Instituições. Rio de Janeiro: FGV, 2002, pp. 191-222.

FORMIGA, N. S. Condutas Anti-sociais e Delitivas: uma Explicação em Termos dos Valores Humanos. Dissertação de Mestradoem Psicologia. Universidade Federal da Paraíba. João Pessoa, 2002a.

FORMIGA, N. S. Os Indicadores do Bom Estudante e sua Relação com os Endogrupos Diários: Perspectivas para uma Prática Educativa Participativa. Revista PsicologiaArgumento, v. 20, n. 31, Curitiba, 2002b, pp.21-27.

FORMIGA, N. S. Um Estudo Intracultural dos Indicadores da Relação Familiar. Revista de Psicologia da Vetor Editora, v. 5, n.1, São Paulo, 2004, pp. 6671.

FORMIGA, N. S.; FACHINI, A. C. Apoio Social e Condutas Desviantes: um Estudo sobre a Consistência Explicativa dos Grupos Cotidianos no Comportamento dos Jovens. III Congresso Científico do Ceulp-Ulbra. Mercado e Cidadania: o Papel da Universidade. Palmas-TO, 21 a 22 de maio de 2003, pp.186-188 [Resumos].

FORMIGA, N. S.; GOUVEIA, V. V. Adaptação e Validação da Escala de Condutas Anti-sociais e Delitivas ao Contexto Brasileiro. Revista Psico, v. 34, n. 2, Porto Alegre, 2003, pp. 367-388.

FORMIGA, N. S.; GOUVEIA, V. V.; VASCONCELOS, T. C.; ANDRADE, I M.; SANTOS, W.S.; PIMENTEL, C. E. Relaçãoentre as Práticas Parentais eos Valores Humanos em Jovens do Ensino Fundamental. III Congresso Norte-Nordeste de Psicologia. Construindo a Psicologia Brasileira: Desafios da Ciência e Prática Psicológica, João Pessoa: PB. 27 a 31 de maio, 2003, p.350 [Resumos].

FORMIGA, N. S; OLIVEIRA, A. R. N.; CURADO, F.; LÜDKE, L.; TEIXEIRA, J.; FACHINI, A. C. Estratégias Educativas na Família e Condutas Antisociais e Delitivas. XXXIII Reunião Anual da Sociedade Brasileira de Psicologia. Psicologia: Compromisso com a Vida. Belo Horizonte-MG: Sociedade Brasileira de Psicologia; 2003, p. 383 [Resumos].

FRAGA, A. B. Corpo, Identidade e Bom Mocismo: o Cotidiano de uma Adolescência Bem Comportada. Belo Horizonte, MG: Autêntica, 2000.

GROSSI, E.J.; PAÍNO, S. G.; FERNÁNDEZ,J.A.; RODRÍGUEZ, F.J.; HERRERO, F. J. Conducta Delictiva y Ámbito Familiar. Endereço da página WEB: http://mww.uniovi.es/ PSi/REIPS/v1n1/articulo9.html. (Consultado em 15 de outubro de 2004). 2000.

GULIONE, E:MOORE, S. Adolescent Risk-taking and the Five-factorMode of Personality. Journal of Adolescent, v. 26, Ohio, 2000, pp. 393-407.

KITSANTAS, A.; WARE, H. W.; MARTINEZ-ARIAS, R. Students' Perception of School Safety: Effects by Community, School Environmentand Substance Use Variables. Journal of Early Adolescence, v. 22, n. 4, Thousand Oaks, 2004, pp. 412-430

LANE, S. M. A Mediação Emocional na Constituição do Psiquismo Humano. In S. M. Lane \& B. B. Sawaia (orgs.). Novas Veredas da Psicologia Social. São Paulo: Brasiliense, 1995.

LOEHLIN, J. C. A Testof J. R. Harris's Theory of Peer Influences on Personality. Journal of Personality and Social Psychology, v. 72, n. 5, Washington, 1997, pp. 1197-1201.

MULVEY, E. P.; CAUFFMAN, E. The Inherent Limits of Predicting Schoo Violence. American Psychologist, v. 56, n. 10, 2001, pp. 797-802.

MUÑOZ-RIVAS, M.; GRAÑA, J. L. L. Factores Familiares de Riesgo y de Protección para el Consumo de Drogas en Adolescentes. Psicothema, $\mathbf{v}$. 13, n. 1, 2002, pp. 87-94.

OMAR, A.; FORMIGA, N. S.; URIBE, H. D.; LÜDKE, L. Correlatos entree Medio Ambiente Familiar y el Desempeño Académico en Adolescentes Argentinos e Brasileños. XXXIII ReuniãoAnual da Sociedade Brasileira de Psicologia. Psicologia: Compromisso com a Vida. Belo Horizonte - MG. 22a 26 de Outubro de 2003, p.351 [Resumos].

OMAR, A; FORMIGA, N. S.; DELGADO, H. U.; SAMPAIO, M. El Impacto de la Personalidad sobre la Autoimagen y la Valoración de las Figuras Modeladoras en Adolescentes Escolares. In V Congresso Internacional de Educação. Os Desafios no Processo de Ensino-aprendizagem. São Luis -MA: Educare, 2004, p. 390

OUTEIRAL, J. O. Adolescer: Estudos sobre Adolescência. Porto Alegre: Artes Médicas, 1994.

PETRAITIS, J.; FLAY, B. R.; MILLER, T.Q. Reviewing Theories of Adolescent Substance Use: Organizing Pieces in the Puzzle. Psychological Bulletin, v. 117, Washington, 1995, pp. 67-86

POLONIA, A. C.; SENNA, S. R. C. M. A Ciência do Desenvolvimento Humano esuas Interfaces com a Educação. In Maria A. Dessen \& Áderson L. Costa Junior e cols. (org.). A Ciência do Desenvolvimento Humano: Tendências Atuais e Perspectivas Futuras. Porto Alegre: Artemed, 2005, pp. 190-209.

REID I B · EDDY I M The Prevention of Antisocial Behavior: some Considerations in the Search for Effective Intenventions. In D. M. Stoff. Breiling; J. D. Maser (orgs.). Handbook of Antisocial Behavior. Canada: John Wiley and Sons, 1997, pp. 343-356.

SCHNEIDER, J. O. Transmissão de Valores de Pais para Filhos: Dimensões do Desejável e do Perceptível. Dissertação de Mestrado em Psicologia. Universidade Federal da Paraíba, João Pessoa, 2001.

STOFF, D. M.; BREILING,J.; MASER, J.D. Handbook of Antisocial Behavior. Canada: John Wiley and Sons, 1997.

SUKHODOLSKY, D. G.; COLUB, A. G.; CROMWELL, E. N. Development and Validation of the Anger Rumination Scale. Personality and Individual Differences, v. 31, Oxford, 2001, pp. 689-700.

TAMAYO, A.; NICAREITA, M.; RIBEIRO, R.; BARBOSA, L. P.G. Prioridades Axiológicas y Consumo de Drogas. Acta Psiquiátrica y Psicológica de la America Latina, v. 4, Buenos Aires, 1995, pp. 300-307.

TORRENTE H. G.; RODRÍGUEZ G. Á. Precedentes Sociofamiliares de

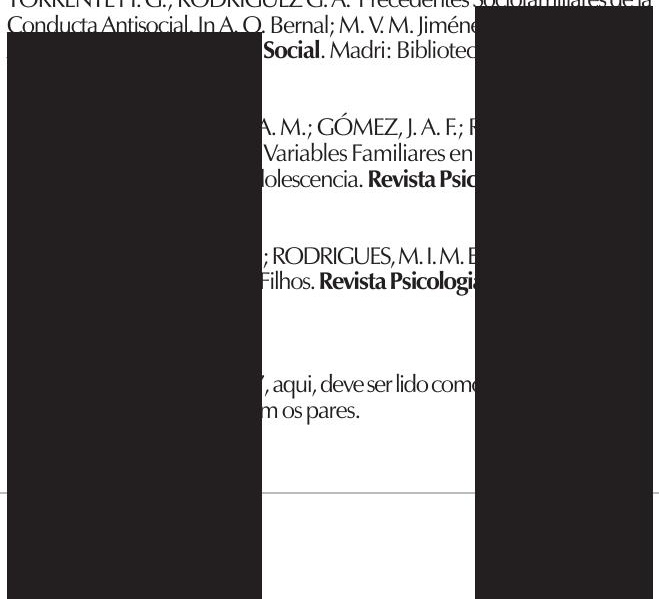

\section{Referências}

